\title{
School-based vaccination in NSW
}

\author{
Kirsten F. Ward $^{\mathrm{A}, \mathrm{D}}$, Robert I. Menzies ${ }^{\mathrm{A}}$, \\ Helen E. Quinn ${ }^{\mathrm{A}, \mathrm{B}}$ and Sue Campbell-Lloyd ${ }^{\mathrm{C}}$ \\ ${ }^{\mathrm{A}}$ National Centre for Immunisation Research and Surveillance, \\ The Children's Hospital at Westmead \\ ${ }^{\mathrm{B}}$ Paediatrics and Child Health, The University of Sydney \\ ${ }^{\mathrm{C}}$ AIDS and Infectious Diseases Branch, NSW Department of Health \\ ${ }^{\mathrm{D} C o r r e s p o n d i n g ~ a u t h o r . E m a i l: k i r s t e n w @ c h w . e d u . a u ~}$
}

\begin{abstract}
Over the past decade the number of recommended and funded vaccines for adolescents has increased, becoming a substantial part of the National Immunisation Program in Australia. In response, NSW has implemented disease-specific vaccination campaigns for both children and adolescents and more recently established a routine high school-based vaccination program to administer vaccines to this often hard to reach group. This paper outlines the history of school-based vaccination in NSW from its commencement in 1971 to coverage from early disease-specific programs, and describes the implementation of the current program of routine vaccination. Substantial coverage has been achieved across the age spectrum 5-17 years, highlighting the effectiveness of the school-based vaccination program in reaching large numbers of adolescents.
\end{abstract}

Schools are a high risk setting for disease transmission and outbreaks due to the close contact of relatively large numbers of children at an age when many have not been previously exposed to common infections. School-aged children commonly suffer high rates of many infectious diseases and they transmit disease to other age groups who are more vulnerable to serious morbidity, such as infants and the elderly. ${ }^{1-7}$ Therefore, school-aged children have been an important target for vaccination programs in Australia and overseas, and in recent years adolescent vaccination programs have become well established in Australia. This report describes the development of the New South Wales (NSW) Adolescent Vaccination Program, its current operation and the vaccination coverage achieved.

\section{History}

The earliest recorded national school-based vaccination services in Australia provided the diphtheria toxoid vaccine from 1932-1936. This was followed by the introduction of the Bacillus of Calmette and Guérin vaccine (BCG for tuberculosis) which was provided through school-based vaccination programs in some jurisdictions from the late 1940s to the mid-1980s. Polio vaccine was also provided in some schools during the 1950s and 1960s as part of larger mass vaccination programs. ${ }^{1,8}$

More recently, school-based vaccination services commenced in NSW in 1971 when the monovalent rubella vaccine was administered to girls in the first year of high school (Table 1). ${ }^{8,9}$ The schoolgirl rubella program was implemented in rural areas by community health staff, while in metropolitan areas an independent team of two school immunisation nurses provided this service. This model continued into the late 1990 s, providing the platform for the change to measles-mumps-rubella (MMR) vaccine from 1994 and the vaccination of boys from 1996. 8 ,9 The National Measles Control Campaign in 1998 brought the second dose of MMR vaccine forward to 4-5 years of age, necessitating a one-off catch-up campaign for the whole of primary school (5-12 years of age). ${ }^{10,11}$ The school-based program for MMR vaccine was then disbanded due to lack of resources.

The National Health and Medical Research Council recommended National Hepatitis B Vaccine Program for children aged 10-13 years was implemented through general practice in NSW from 1999 until it was incorporated into the Adolescent Vaccination Program in 2004. ${ }^{12}$ An evaluation undertaken in 2001 found high levels of awareness and support among parents but low coverage (18\%) through private sector service provision. ${ }^{12,13}$

The National Meningococcal C Vaccination Program targeted all children and young people aged 12 months to 19 years and commenced in January 2003. ${ }^{14,15}$ In NSW, this was implemented through a whole of high school vaccination program in 2003 and a whole of primary school program in 2004 . This was the catalyst for the reestablishment of routine school-based vaccination in NSW through the Adolescent Vaccination Program.

Due to increased pertussis notifications in high schoolaged children a whole of high school vaccination program with diphtheria-tetanus-pertussis (dTpa) vaccine was conducted across NSW in 2004, ${ }^{16}$ and continued in 2005 targeting Year 7 students only. The dTpa vaccine was reintroduced for Year 10 students in 2009 and, following a recommendation by the Australian Technical Advisory Group on Immunisation, routine vaccination of Year 7 students commenced in 2010 with catch-up of students in 
Table 1. History of vaccines delivered through universal school-based vaccination programs in NSW

\begin{tabular}{|c|c|c|}
\hline Year & Vaccine & School year \\
\hline 1971-1994 & Rubella (monovalent) (single dose) & Year 7 (Girls only) \\
\hline \multirow[t]{2}{*}{ 1994-1997 } & Measles-mumps-rubella (MMR) (single dose) & Year 7 (Girls only in 1994 and 1995) \\
\hline & & (Both boys and girls in 1996 and 1997) \\
\hline 1998 & Catch-up MMR (single dose) & Whole of primary school (Years K-6) \\
\hline 1999-2003 & Hepatitis B (3 dose) & Delivered through general practitioners \\
\hline \multirow[t]{2}{*}{ 2003-2004 } & Meningococcal C (single dose) & Whole of high school (2003) (Years 7-12) \\
\hline & & Whole of primary and high school (2004) (Years K-12) \\
\hline \multirow[t]{2}{*}{ 2004-2005 } & Diphtheria-tetanus-pertussis (dTpa) (single dose) & Whole of high school (2004) (Years 7-12) \\
\hline & & Year 7 only (2005) \\
\hline 2004-2012 & Hepatitis B (2 dose) & Year $7^{\mathrm{a}}$ \\
\hline 2006-ongoing & Varicella zoster (VZV) (single dose) & Year $7^{\mathrm{b}}$ \\
\hline \multirow[t]{3}{*}{ 2007-ongoing } & Human papillomavirus (HPV) (3 dose) & Years 10-12 (2007) \\
\hline & & Years 7-10 (2008) \\
\hline & & Year 7 only (from 2009) \\
\hline \multirow[t]{2}{*}{ 2009-ongoing } & Diphtheria-tetanus-pertussis (dTpa) (single dose) & Year 10 (2009-2012) \\
\hline & & Year 7 (from 2010) \\
\hline
\end{tabular}

Years 8-10 to be conducted over a 2-year period (20102012). Hepatitis B vaccine was also introduced in 2004 for Year 7 students, and will continue until the end of 2012 when all children of that age will have been vaccinated as infants. Varicella zoster vaccine was introduced in 2006 for students in Year 7 with no prior history of varicella vaccination or disease.

The National Human Papillomavirus (HPV) Program targeted females aged 12-26 years. Between 2007 and 2009 this consisted of a time-limited catch-up program delivered through schools, general practices and community immunisation services. ${ }^{17}$ In NSW, the school-based catch-up program commenced in April 2007 for girls in Years 10-12 and continued in 2008 for girls in Years 7-10. Since 2009, HPV vaccine has been provided routinely through the Adolescent Vaccination Program for girls in Year 7 (Table 1).

\section{Current NSW Adolescent Vaccination Program}

The Australian Government provides funding to each state and territory for the purchase of vaccines on the National Immunisation Program, including all vaccines administered through the NSW Adolescent Vaccination Program. It also provides a contribution to service provision. The NSW Government provides funding for training and service delivery to enable the implementation of the Adolescent Vaccination Program in all public and private high schools. Overall coordination is provided by the NSW Department of Health Immunisation Unit, while delivery is conducted through the area health services (AHSs). ${ }^{18}$
A minority of high schools refuse to participate due to a philosophical objection to vaccination. These schools are provided with information about the program to distribute to parents; those parents who would like for their child to be vaccinated are advised to visit their general practitioner. ${ }^{19}$

Each high school holds 3-4 vaccination clinics during each school year. Scheduling of vaccines is based around the 3-dose HPV course with other vaccines organised to minimise the number of injections per visit and to meet required dose intervals. Clinic dates are organised by AHSs in the year prior to implementation. Each school is contacted 2-3 days prior to a clinic to ascertain the approximate numbers of students requiring vaccination and to discuss logistical arrangements.

All registered nurses who administer vaccines in the NSW Adolescent Vaccination Program are authorised nurse immunisers. They have completed specialist training and attend annual cardiopulmonary resuscitation training and seminars to ensure they are up to date with best practice immunisation policy. ${ }^{20}$ Since 2007 in most AHSs, school immunisation nurses have been supported by St John Ambulance (NSW) Immunisation Program volunteers who assist students both prior to and after vaccination. ${ }^{21}$ Each school clinic is staffed by a minimum of two authorised nurse immunisers, a team leader/coordinator and rostered St John Ambulance (NSW) volunteers if they are available. In addition, a number of school staff members are required to distribute consent forms and supervise the students. 
Since 2003, AHSs have provided adolescent vaccines in Intensive English Centres in Sydney metropolitan areas. These centres provide tuition and welfare programs to high school-aged students who have recently arrived in Australia and whose first language is not English. ${ }^{22}$ The services differ slightly from the routine program, as Intensive English Centres are visited each term and all students are offered catch-up vaccination for varicella, hepatitis B, meningococcal C and MMR, as well as dTpa and HPV as per the Adolescent Vaccination Program cohorts.

The NSW Adolescent Vaccination Program 2010 Protocols $^{18}$ provide the policy framework for the consistent, safe and effective implementation of the NSW Adolescent Vaccination Program. This includes detailed vaccine management, catch-up and post-vaccination care procedures for school-based clinics. The transport and storage of vaccines for the NSW Adolescent Vaccination Program is undertaken in accordance with National Vaccine Storage Guidelines - Strive for Five 2005. ${ }^{23}$ Vaccinated students must remain in the vicinity of the place of vaccination and under adult supervision for at least 15 minutes following vaccination. School-based immunisation nurses are required to remain at the school for 15 minutes after the last student has been vaccinated. Students who miss a dose through illness or absenteeism are offered catch-up vaccination through AHSs or general practice.

\section{Consent}

NSW education authorities have advised that all students, including those aged 18 years and over, require written vaccine-specific consent signed by their parent/guardian. Students can refuse vaccination even if prior written consent has been provided by their parent/guardian.

\section{Resources}

Program resources, including parent information kits, templates of letters and newsletter articles, are developed by the NSW Department of Health for use by AHSs. These resources are designed to assist AHSs in communicating with schools about the Adolescent Vaccination Program. A Parent Information Kit for each type of vaccine is provided in a colour-coded envelope and contains: questions and answers about the vaccine/disease; a consent form with a record of vaccination; a privacy leaflet; and contacts for all NSW public health units. A Student Advice Card is distributed immediately prior to vaccination, outlining what students should expect in the vaccination encounter. Additionally, the Adolescent Vaccination Program section of the NSW Health website has general information for both parents and students. ${ }^{19}$ Some AHSs may develop additional communication and/or promotional materials for use in their area.

\section{Reporting}

From 2003, vaccines provided through the NSW Adolescent Vaccination Program have been recorded on a disease-specific record of vaccination. This is provided to students following vaccination with a duplicate copy kept at the AHS. Data are aggregated by the AHS and forwarded to NSW Health each quarter. To enhance data accessibility and useability, scannable consent/vaccination record forms have been phased in since 2009 .

NSW Health has developed an interim state-based immunisation register to record HPV vaccines administered in NSW schools. This has allowed the electronic transfer of data to the National HPV Register. As part of the NSW National Notifiable Diseases Database upgrade, NSW Health is developing a web-based, statewide immunisation register, primarily to record all adolescent vaccines administered in schools. The register is expected to be fully operational by mid-2011.

Adverse events following immunisation are closely monitored by immunisation teams at schools and notified immediately to the public health unit. AHSs are required to report all serious adverse events to the NSW Department of Health. ${ }^{18}$ An overview of the national assessment and reporting processes for adverse events following immunisation notified by public health units is published in the accompanying paper in this issue $e^{24}$ as well as in other national publications. ${ }^{25}$

Vaccine wastage is recorded for each school clinic. Data are aggregated at an AHS level and provided quarterly to the NSW Department of Health Immunisation Unit.

\section{Coverage}

The earliest available data describing vaccine coverage for NSW adolescents is from the National Hepatitis B Vaccine Program (1999-2000). Coverage from this general practice program was measured through a telephone survey of the parents/carers of NSW children aged 10-13 years and was estimated as $18 \%{ }^{12}$

Coverage achieved by the National Measles Control Campaign was measured through standardised data collected at the time of vaccination. Coverage for NSW primary school-aged children was estimated as $75.4 \%$. More detailed results of this campaign are reported elsewhere. ${ }^{11}$

Coverage for early disease-specific and time-limited school-based vaccination programs in NSW (meningococcal C and dTpa) are presented in Table 2. During the 2003-2004 National Meningococcal C Vaccination Program, 3186 NSW schools were visited and a total of 823197 students were vaccinated. The first year of school (Kindergarten) had significantly lower coverage 
Table 2. Coverage for National Meningococcal C (2003-2004) and diphtheria, tetanus, pertussis (dTpa) (2004) school-based vaccination programs, NSW

\begin{tabular}{|c|c|c|c|}
\hline School year & Age (years) & $\begin{array}{c}\text { Coverage Meningococcal C } \\
(2003-2004)^{\mathrm{a}} \\
\% \\
N=823197\end{array}$ & $\begin{array}{c}\text { Coverage dTpa } \\
(2004) \\
\% \\
N=274364\end{array}$ \\
\hline \multicolumn{4}{|l|}{ Kindergarten } \\
\hline & 5 & 44 & $\mathrm{n} / \mathrm{a}$ \\
\hline \multicolumn{4}{|c|}{ Primary school } \\
\hline 1 & 6 & 71 & $\mathrm{n} / \mathrm{a}$ \\
\hline 2 & 7 & 74 & $\mathrm{n} / \mathrm{a}$ \\
\hline 3 & 8 & 76 & $\mathrm{n} / \mathrm{a}$ \\
\hline 4 & 9 & 77 & $\mathrm{n} / \mathrm{a}$ \\
\hline 5 & 10 & 80 & $\mathrm{n} / \mathrm{a}$ \\
\hline 6 & 11 & 76 & $\mathrm{n} / \mathrm{a}$ \\
\hline \multicolumn{4}{|l|}{ High school } \\
\hline 7 & 12 & 79 & 64 \\
\hline 8 & 13 & 79 & 64 \\
\hline 9 & 14 & 78 & 62 \\
\hline 10 & 15 & 76 & 56 \\
\hline 11 & 16 & 75 & 41 \\
\hline 12 & 17 & 67 & 41 \\
\hline
\end{tabular}

$(44 \%, 72076)$ than primary $(76 \%, 401363)$ and secondary schools $(76 \%, 349758)(p<0.001)$ as many children aged $4-5$ years were vaccinated by general practitioners. In primary schools there was a statistically significant trend of coverage increasing with increasing school year $(p<0.001)$, while in high school this trend was reversed $(p<0.001)$. When examined by AHS, combined coverage of both primary and high schools was significantly higher in the rural AHSs (80\%) compared with metropolitan AHSs $(73 \%)(p<0.001)$, ranging from $69 \%$ to $85 \%$ (Table 2).

During the 2004 dTpa vaccination program, 274364 $(56 \%)$ eligible children were vaccinated. Coverage varied by AHS, ranging from $48 \%$ to $63 \%$. As there were no program delivery issues unique to any AHS, the variation in coverage is likely to have occurred due to differences in the demographics of the population in that area, such as conscientious objection, which affect coverage in other age groups ${ }^{26}$ Coverage may also have been affected by the National Health and Medical Research Council recommendation that children who had received $\mathrm{dT}$ vaccine in the previous 5 years were not eligible to receive dTpa vaccine through this program. Coverage was similar in metropolitan and regional schools (56\% and 55\% respectively) and only slightly lower in remote schools (49\%), although this difference was statistically significant $(p<0.001)$. There was a statistically significant association between school type and immunisation coverage $(p<0.001)$, with higher coverage seen in Catholic schools
(60\%) compared with government (55\%) and independent schools $(50 \%)$. This association was not confounded by school location or the socioeconomic status of the local area. Immunisation coverage was similar in schools of varying size. Coverage decreased with higher school years, particularly in Years 11 and 12, with a statistically significant inverse trend in coverage and school year $(p<0.001)$.

The re-introduction of dTpa into the Adolescent Vaccination Program from 2009 resulted in 68\% coverage of eligible Year 10 students with coverage higher than the 2004 program across all AHSs (range 61-71\%). Other vaccines delivered through the Adolescent Vaccination Program in 2009 targeted Year 7 students, with statewide coverage ranging from $34 \%$ for varicella vaccine (in students with no previous clinical disease) to $80 \%$ for HPV (dose 1). Coverage is consistently higher for the first dose of both hepatitis B (63\% versus 50\%) and HPV ( $80 \%$ versus $77 \%$ versus $69 \%$ ) vaccines which require multiple doses. ${ }^{27}$ Further detail on coverage for the 2009 Adolescent Vaccination Program is presented in the accompanying paper in this issue. ${ }^{27}$

\section{Discussion}

There are many challenges in vaccinating adolescents in comparison to younger age groups, including their increased mobility, limited visits to general practice and the need to obtain consent from parents who are not present 
at the vaccination. ${ }^{28,29}$ Despite these challenges, schoolbased vaccination in NSW has achieved high coverage, which is similar to or better than that achieved in other Australian jurisdictions ${ }^{30-33}$ and higher than in settings where adolescent vaccines are implemented through primary care. ${ }^{34,35}$ The higher coverage consistently achieved in the early high school years has resulted in a transition towards delivering the majority of routine vaccines in Year 7. The implementation of the statewide adolescent vaccination register will be another substantial improvement to the program as it will improve access to individual vaccination records and enhance accuracy of coverage data used to monitor program effectiveness.

\section{Conclusion}

The NSW Adolescent Vaccination Program has evolved considerably over the last decade in response to available evidence and increased availability of and recommendations for adolescent vaccines. Integral to its success is the collaborative and coordinated approach to service delivery, the cooperation of the NSW education authorities and school principals, and the highly skilled workforce involved in its implementation.

\section{Acknowledgments}

The National Centre for Immunisation Research and Surveillance is supported by The Australian Government Department of Health and Ageing, the NSW Department of Health and The Children's Hospital at Westmead.

We acknowledge the dedication and work of the large number of individuals who have been responsible for the planning and implementation of school-based vaccination in NSW over the years.

\section{References}

1. Population Health Division. The Health of the people of New South Wales - Report of the Chief Health Officer, Data Book Communicable Diseases. North Sydney: NSW Department of Health; 2008.

2. Bisgard KM, Pascual FB, Ehresmann KR, Miller CA, Cianfrini C, Jennings CE et al. Infant pertussis: who was the source? Pediatr Infect Dis J 2004; 23(11): 985-9. doi:10.1097/01.inf.0000145263. $37198.2 \mathrm{~b}$

3. Glass K, Barnes B. How much would closing schools reduce transmission during an influenza pandemic? Epidemiology 2007; 18(5): 623-8. doi:10.1097/EDE.0b013e31812713b4

4. King JC, Jr, Cummings GE, Stoddard J, Readmond BX, Magder LS, Stong M et al. A pilot study of the effectiveness of a school-based influenza vaccination program. Pediatrics 2005; 116(6): e868-73. doi:10.1542/peds.2005-1301

5. Marshall H, Ryan P, Roberton D. Uptake of varicella vaccine - a cross sectional survey of parental attitudes to nationally recommended but unfunded varicella immunisation. Vaccine 2005; 23(46-7): 5389-97. doi:10.1016/j.vaccine.2005.05.033

6. Parker AA, Staggs W, Dayan GH, Ortega-Sánchez IR, Rota PA, Lowe L et al. Implications of a 2005 measles outbreak in Indiana for sustained elimination of measles in the United States. N Engl $J$ Med 2006; 355(5): 447-55. doi:10.1056/NEJMoa060775
7. Reichert TA, Sugaya N, Fedson DS, Glezen WP, Simonsen L, Tashiro M. The Japanese experience with vaccinating schoolchildren against influenza. N Engl J Med 2001; 344(12): 889-96. doi:10.1056/NEJM200103223441204

8. Gidding HF, Burgess MA, Kempe AE. A short history of vaccination in Australia [erratum appears in Med J Aust 2001; 174(5): 260]. Med J Aust 2001; 174(1): 37-40.

9. Coulter C, Wood R, Robson J. Rubella infection in pregnancy. Commun Dis Intell 1999; 23(4): 93-6.

10. Commonwealth Department of Health and Aged Care. Immunise Australia Program: measles control campaign. Commun Dis Intell 1998; 22(8): 156.

11. Commonwealth Department of Health and Aged Care. Let's work together to beat measles: report on Australia's measles control campaign. Canberra: Commonwealth Department of Health and Aged Care; 2000.

12. Correll PK, Hayen A, Eyeson-Annan M. Hepatitis B immunisation in children aged 10-13 years in New South Wales, 2001. N S W Public Health Bull 2003; 14(1-2): 17-20. doi:10.1071/ NB03005

13. NSW Department of Health. Internal Report: NSW Adolescent Vaccination Program. NSW school-based implementation May-December 2004. Final Report. Unpublished; 2007.

14. Patterson K. Media Release: One million children to get Meningococcal C vaccine sooner. 2002. Available from: http://www.health.gov.au/internet/main/publishing.nsf/ Content/health-mediarel-yr2002-kp-kp02128.htm (Cited 9 April 2010.)

15. NSW Department of Health. Internal Report: National Meningococcal C Vaccination Program. NSW School-based Implementation August 2003-December 2004. Unpublished; 2005.

16. Abbott T. Media Release: $\$ 5.6$ million to fight NSW whooping cough epidemic. 2004. Available from: http://www.health.gov. $\mathrm{au} /$ internet/ministers/publishing.nsf/Content/health-mediare 1-yr2004-ta-abb031.htm?OpenDocument\&yr $=2004 \& \mathrm{mth}=3$ (Cited 13 April 2010.)

17. Australian Government Department of Health and Ageing. Human Papillomavirus (HPV). 2009. Available from: http:// www.health.gov.au/internet/immunise/publishing.nsf/Content/ immunise-hpv (Cited 12 April 2010.)

18. NSW Department of Health. NSW Adolescent Vaccination Program 2010 Protocols. Sydney: NSW Government; 2010.

19. NSW Department of Health. School Based Immunisation Programs. 2010. Available from: http://www.health.nsw. gov.au/PublicHealth/Immunisation/school_prog/index. asp\#para_2 (Cited 12 April 2010.)

20. NSW Department of Health. Policy Directive: Immunisation Services - Authority for Registered Nurses PD2008_033. 2008. Sydney: NSW Government; 2008.

21. St John Ambulance New South Wales. Immunisation Program. 2010. Available from: http://www.stjohnnsw.com.au/t_ip.html (Cited 12 April 2010.)

22. NSW Department of Education and Training. NSW Public Schools. Secondary Schools - Intensive English Centres. 2009. Available from: http://www.schools.nsw.edu.au/ gotoschool/types/intensivecentre/index.php (Cited 12 April 2010.) 
23. Australian Government Department of Health and Ageing. National Vaccine Storage Guidelines: Strive for Five. Canberra: Commonwealth Government; 2005.

24. Mahajan D, Campbell-Lloyd S, Roomiani I, Menzies RI. NSW annual adverse events following immunisation report, 2009. NS W Public Health Bull 2010; 21(9-10): 224-33. doi:10.1071/ NB10048

25. Lawrence G, Gold MS, Hill R, Deeks S, Glasswell A, McIntyre PB. Annual report: surveillance of adverse events following immunisation in Australia, 2007. Commun Dis Intell 2008; 32(4): 371-87.

26. Hull B, McIntyre P. Mapping immunisation coverage and conscientious objectors to immunisation in NSW. NS W Public Health Bull 2003; 14(1-2): 8-12. doi:10.1071/NB03003

27. Hull B, Dey A, Mahajan D, Campbell-Lloyd S, Menzies RI, McIntyre PB. NSW Annual Immunisation Coverage Report, 2009. N S W Public Health Bull 2010; 21(9-10): 210-23. doi:10.1071/NB10045

28. Booth ML, Knox S, Kang M. Encounters between adolescents and general practice in Australia. J Paediatr Child Health 2008; 44(12): 699-705. doi:10.1111/j.1440-1754.2008.01409.x

29. Humiston SG, Rosenthal SL. Challenges to vaccinating adolescents: vaccine implementation issues. Pediatr Infect Dis J 2005; 24(6, Suppl.): S134-40.

30. Queensland Government. Evaluation of the School-based Vaccination Program (2007-2009) Stakeholders' Report. Brisbane: Queensland Government; 2010.
31. Brotherton JM, Deeks SL, Campbell-Lloyd S, Misrachi A, Passaris I, Peterson K et al. Interim estimates of human papillomavirus vaccination coverage in the school-based program in Australia. Commun Dis Intell 2008; 32(4): 457-61.

32. Dowse G, Watson T, Kwan K, Bowen S. Epidemiology of the 2004 pertussis epidemic in Western Australia and experience with mass dTpa immunisation of high schools students as a control measure. Piecing together the Jigsaw: Communicable Diseases Control Conference; May 2005; Sydney, Australia.

33. Watson M, Shaw D, Molchanoff L, McInnes C. Challenges, lessons learned and results following the implementation of a human papilloma virus school vaccination program in South Australia. Aust N Z J Public Health 2009; 33(4): 365-70. doi:10.1111/j.1753-6405.2009.00409.x

34. Centers for Disease Control and Prevention. National, state, and local area vaccination coverage among adolescents aged 13-17 years - United States, 2008. MMWR Morb Mortal Wkly Rep 2009; 58(36): 997-1001.

35. Centers for Disease Control and Prevention. Recommended immunization schedules for persons aged 0 through 18 years United States, 2010. MMWR Morb Mortal Wkly Rep 2010; 58(51-52): 1-4. 